\title{
Lymphomatous meningitis in AIDS-related systemic non-Hodgkin's lymphoma: a report of eight cases
}

\author{
R H Enting, R A J Esselink, P Portegies
}

\begin{abstract}
Meningeal involvement occurred in eight (22\%) of 36 adult patients with AIDSrelated systemic non-Hodgkin's lymphoma, seen over a 10-year period. Clinical symptoms consisted of cranial nerve palsies, radicular involvement, headache or diffuse encephalopathy. CSF examination established the diagnosis in all cases. Systemic disease had been diagnosed seven to 33 weeks before lymphomatous meningitis in six patients, whereas in the remaining two patients diagnoses of systemic and meningeal disease were made simultaneously. All patients had intermediate or high grade lymphomas and widespread disease. In contrast to non-AIDS related lymphomas, bone marrow involvement at initial staging cannot be used to select patients for prophylactic treatment, as seven of our eight patients had no initial bone marrow involvement. In this restrospective review, prognosis of $\mathbf{l y m}$ phomatous meningitis was extremely poor, with a mean survival of only five weeks. Survival of patients with systemic lymphoma who eventually developed lymphomatous meningitis was $4 \cdot 0$ months compared with $7 \cdot 2$ months for those who did not. Lymphomatous meningitis appears to have the worst outcome of all AIDS-related neurological complications, regardless of treatment.
\end{abstract}

$(\mathcal{F}$ Neurol Neurosurg Psychiatry 1994;57:150-153)

The acquired immune deficiency syndrome (AIDS) is associated with an increased incidence of non-Hodgkin's lymphoma. These lymphomas are usually systemic high-grade B-cell-lymphomas (immunoblastic lymphoma, Burkitt's lymphoma) and primary lymphoma of the brain. ${ }^{12}$ Systemic high grade lymphomas have been reported in $2.3 \%$ of cases of AIDS, compared with a prevalence of $0.05 \%$ in the general population. ${ }^{3}$

In non-AIDS-related systemic lymphomas CNS involvement is not a frequent complication and occurs almost exclusively in intermediate and high grade malignancies (according to the Working Formulation). ${ }^{4-6}$ Meningeal involvement has been found in $2-8 \%$, cerebral in 1-2.5\%, and epidural in 0.5-6\%. ${ }^{4-6}$

Meningeal involvement occurs far more frequently in AIDS-related systemic lym- phomas and has been reported in $12-26 \%$ at the initial presentation. ${ }^{7-9}$ Data on meningeal relapse after treatment are sparse.

We have reviewed the records of all patients with HIV-related neurological complications examined at the Academic Medical Centre in Amsterdam in the period of September 1982 to September 1992. We report the clinical findings, course, treatment and histopathologic findings of eight patients with AIDS-related systemic non-Hodgkin's lymphoma and meningeal involvement.

\section{Patients and methods}

From a review of the medical records of all HIV-infected patients seen for neurological complications $(n=635)$ in the period of September 1982 to September 1992 we identified eight cases of lymphomatous meningitis in AIDS-related systemic non-Hodgkin's lymphoma. Prevalence of this neurological complication is $1.2 \%$ among all neurological complications. To find all cases of AIDSrelated systemic non-Hogkin's lymphoma during this period a computerised search was performed of the combined discharge diagnoses of HIV-infection/AIDS and nonHodgkin's lymphoma. This search yielded 36 patients. We eventually reviewed the medical records of these patients for survival data. Examination of the spinal fluid has not been part of the routine staging procedures until September 1992. Neurological and spinal fluid examination in these 36 patients were performed when neurological abnormalities were present. Clinical evaluation included age, sex, AIDS risk factors, previous AIDSrelated complications, CD4-positive lymphocyte counts (CD4 count), clinical stage at presentation - Ann Arbor stage I-IV (stage I: involvement of a single lymph node region or of a single parenchymal organ; stage IV: disseminated foci of one or more parenchymal organs with or without lymph node involvement or a single lesion in liver or bone marrow; the presence of fever, night sweats or weight loss is denoted by the suffix letter B), ${ }^{10}$ histology (Working Formulation and Kiel classification $^{1112}$ ), treatment regimens, response to initial systemic therapy, time course to development of meningeal involvement, signs and symptoms of meningeal involvement, spinal fluid findings, radiological findings, therapy and survival from the date of the diagnostic procedure. Necropsy was performed on four patients. 
Table Characteristics of eight patients with lymphomatous meningitis and AIDS

\begin{tabular}{|c|c|c|c|c|c|c|c|c|}
\hline Patients & 1 & 2 & 3 & 4 & 5 & 6 & 7 & 8 \\
\hline $\begin{array}{l}\text { Sex } \\
\text { Age } \\
\text { Risk group } \\
\text { Histology }\end{array}$ & $\begin{array}{l}\text { Male } \\
57 \\
\text { hs } \\
\text { IB/ } \\
\text { HG }\end{array}$ & $\begin{array}{l}\text { Male } \\
30 \\
\text { hs } \\
\text { B/ } \\
\text { HG }\end{array}$ & $\begin{array}{l}\text { Female } \\
49 \\
- \\
\text { B/ } \\
\text { HG }\end{array}$ & $\begin{array}{l}\text { Male } \\
29 \\
- \\
\text { CBIB } \\
\geqslant \text { IG }\end{array}$ & $\begin{array}{l}\text { Male } \\
30 \\
\text { hs } \\
\text { LB/ } \\
\text { HG }\end{array}$ & $\begin{array}{l}\text { Male } \\
30 \\
\text { ivd } \\
\text { IB/ } \\
\text { HG }\end{array}$ & $\begin{array}{l}\text { Male } \\
46 \\
\text { hs } \\
\text { CB/ } \\
\geqslant \text { IG }\end{array}$ & $\begin{array}{l}\text { Male } \\
32 \\
\text { hs } \\
\text { B/ } \\
\text { HG }\end{array}$ \\
\hline $\begin{array}{l}\text { Stage (Ann Arbor) } \\
\text { CD4 count while systemic NHL } \\
\text { CDC classification }\end{array}$ & $\begin{array}{l}\text { IVb } \\
0 \cdot 1 \\
\text { III }\end{array}$ & $\begin{array}{l}\text { IVb } \\
0.03 \\
\text { IVA }\end{array}$ & $\begin{array}{l}\text { IVb } \\
0 \cdot 14 \\
\text { III }\end{array}$ & $\begin{array}{l}\text { IVb } \\
0.08 \\
\text { IVCI }\end{array}$ & $\begin{array}{l}\text { Ib } \\
0 \cdot 23 \\
\text { III }\end{array}$ & $\begin{array}{l}\text { IVb } \\
0 \cdot 4 \\
\text { IVCI }\end{array}$ & $\begin{array}{l}\text { IVb } \\
0.01 \\
\text { IVD }\end{array}$ & $\begin{array}{l}\text { IVb } \\
0.66 \\
\text { III }\end{array}$ \\
\hline Bone marrow infiltration & - & IVA & II & IVC & - & - & & + \\
\hline $\begin{array}{l}\text { Time to meningitis in weeks } \\
\text { CD4 count while LM } \\
\text { Therapy }\end{array}$ & $\begin{array}{l}21 \\
0.03 \\
-\end{array}$ & $\begin{array}{l}14 \\
0.02 \\
\text { MTX } \\
6 x\end{array}$ & $\begin{array}{l}7 \\
0 \cdot 05 \\
\text { MTX } \\
\mathbf{8 x}\end{array}$ & $\begin{array}{l}15 \\
0 \cdot 01 \\
\text { MTX } \\
8 x\end{array}$ & $\begin{array}{l}33 \\
0.03 \\
\text { MTX } \\
5 x \\
\text { RT }\end{array}$ & $\begin{array}{l}0 \\
\text { id } \\
\text { MTX } \\
7 x\end{array}$ & $\begin{array}{l}13 \\
0.01 \\
-\end{array}$ & $\begin{array}{l}0 \\
\text { id } \\
\text { MTX } \\
\text { lx } \\
\text { RT }\end{array}$ \\
\hline Survival in weeks & $11 \mathrm{~d}$ & 4 & 5 & 8 & 4 & 14 & $5 d$ & 2 \\
\hline
\end{tabular}

- = No member of known risk groups; hs = homosexual; ivd = intravenous drug abuse; IB = immunoblastic lymphoma (Kiel classification); $\mathbf{B}=$ Burkitt's lymphoma; $\mathbf{L B}=$ lymphoblastic lymphoma; $\mathrm{CB}=$ centroblastic lymphoma; HG $=$ high grade classification); $B=$ Burkitt's lymphoma; $L B=$ lymphoblastic lymphoma; $C B=$ centroblastic lymphoma; HG $=$ high grade
(Working Formulation); IG = intermediate grade; LM = lymphomatous meningitis; MTX = intrathecal methotrexate; Working Formulation); IG = intermediate grade; $L M=$

CD4 counts in $10^{9} / 1$ are given for the date of initial presentation of systemic lymphoma, and for the date of meningeal involvement.

\section{Results}

Thirty-six patients with systemic nonHodgkin's lymphoma and AIDS were seen in the Academic Medical Centre of Amsterdam in a 10-year period. Meningeal involvement occurred in eight $(22 \%)$ of all patients with systemic lymphoma. Two patients had lymphomatous meningitis at the initial presentation of systemic lymphoma and six developed lymphomatous meningitis.

Seven male patients and one female patient had a mean age of 38 years (range 29-57 years). Five men were homosexual, one was an intravenous drug abuser and two patients probably had been infected by heterosexual contacts. An AIDS-diagnosing event had preceded the onset of systemic lymphoma in three patients; one patient had been diagnosed with Pneumocystis carinii pneumonia and Candida oesophagitis, the second patient with Kaposi's sarcoma, and the third with Candida oesophagitis. The mean CD4 count at the time of diagnosis of systemic disease was $0.2 \times 10^{9} / 1$ (range $0.01-0.66 \times 10^{9} / 1$ ) (normal: $0.5-1.57 \times 10^{9} / 1$ ) (table)

Systemic non-Hodgkin's lymphoma had been diagnosed in all patients before or simultaneously with meningeal involvement. Histological examination revealed B-cell lymphomas in seven patients; in one patient a Bcell origin could not be proved. Six patients had high grade lymphoma (according to the Working Formulation), three of them had Burkitt's lymphoma, two of them immunoblastic lymphoma and one lymphoblastic lymphoma. The other two patients had at least intermediate grade lymphoma, one of them had a mixed immunoblastic/centroblastic lymphoma, the other one had a centroblastic lymphoma. We did not find any case of low grade lymphoma with meningeal involvement.

Clinical staging using the Ann Arbor classification was performed in all patients; seven patients had stage IVb disease and one patient had stage Ib disease. All patients had bone marrow biopsy for staging procedures, only one patient had bone marrow infiltration. The general condition was good in four patients, fair in three and poor in one.
Six patients in whom systemic lymphoma had been found before meningeal involvement occurred were treated with two to four CNOP (cyclophosphamide, mitoxantrone, vincristine, prednisone) regimens. One had progressive lymphoma and treatment was switched to DAP (dexamethasone, cytarabine, cisplatin) regimens. In four patients (1, $2,4,6)$ antiretroviral medication was discontinued during chemotherapy, in the remaining four patients zidovudine was never started. One patient had a complete remission (2), another had a partial remission (5), and four had progressive disease. The mean interval between the diagnosis of systemic lymphoma and meningeal infiltration was 13 weeks (range 0-33 weeks). The CD4 counts had by then decreased to a mean value of $0.15 \times 10^{9} / 1$.

Six patients presented with a cranial nerve palsy, in three of them multiple cranial nerves were involved (the abducens nerve was involved five times; other nerves involved: $\mathbf{N}$ II, III, V, VII, IX, X). One patient presented with spinal root dysfunction. One patient had a diffuse encephalopathy only. Accompanying symptoms in the other seven patients consisted of headache $(n=4)$, vomiting $(n=4)$ and/or diffuse encephalopathy $(n=3)$. The general condition had often deteriorated; the clinical condition was good in one patient, fair in three and poor in four patients.

Metastatic meningeal involvement was found by CSF examination in all patients. In seven patients the first lumbar puncture revealed pathological cells. One patient had manifested an abducens palsy 5 months before proven meningeal involvement. CSF examination had been performed five times, but no malignant cells were found. He eventually developed multiple cranial nerve palsies; re-examination of spinal fluid then revealed lymphoma cells. No further specific abnormalities of the spinal fluid were found; a slight to severe pleiocytosis was always present (range 6-250 leukocytes per $\mathrm{mm}^{3}$ ), protein content was elevated in four patients (mean $0.7 \mathrm{~g} / \mathrm{l}$, range $0.16-1.51 \mathrm{~g} / \mathrm{l}$ ), hypoglycorrhagia was found in three patients. 
CT scanning of the brain before and after administration of iodinated contrast was performed in all patients. In four patients no abnormalities were found, in the other four patients only mild atrophy was found.

All our patients did poorly, either with or without treatment. The average survival was only five weeks (range 5 days-14 weeks). The mean survival of these patients from the date of diagnosis of systemic disease was $4 \cdot 0$ months (95\% cofidence interval: $2 \cdot 1-5 \cdot 9$ months). Two patients $(1,7)$ with progressive systemic disease and poor clinical condition refused treatment. They died 5 and 11 days after the diagnostic procedure.

Treatment data are available in six patients. Five patients (2-6) had an Ommaya reservoir implanted and were treated with intraventricular methotrexate. One patient (5) received additional irradiation on the base of the skull. Two of the five patients $(2,6)$ had a short-lived (one to two weeks) and slight clinical improvement. Two patients $(4,5)$ had a short-lived (one to three weeks) stabilisation of neurological symptoms. One patient developed progressive disease, consisting of hemiparesis and hemihypesthesia (3). One patient (8) was treated with intrathecal methotrexate and steroids once and he started with whole brain radiation, but neurological signs and symptoms progressed and treatment was discontinued. No lymphoma cells could be detected in the CSF of four patients $(2,3,4,6)$ after a mean duration of treatment of ten days, but in two patients $(4,6)$ pathological cells recurred. In two patients $(5,8)$ pathological cells remained present.

Systemic chemotherapy was continued in three patients $(3,4,5)$ and was started in two patients $(6,8)$. In the sixth patient (2) systemic treatment was not reinstituted; a systemic relapse was not present. Two $(3,6)$ received CNOP regimens, two $(4,5)$ received DAP regimes and one patient (8) received vincristine only. In four patients treatment eventually had to be discontinued because of progressive $(5,8)$ or recurrent $(4,6)$ lymphomatous meningitis, all of whom also had progressive systemic disease. In one patient CSF turned tumour-negative, but neurological symptoms progressed, and she died of progressive systemic and meningeal disease (3). In the sixth patient CSF also turned negative, but he died of a status epilepticus (2). At necropsy he showed no systemic or meningeal disease.

To compare the mean survival of the patients who developed lymphomatous meningitis to the survival of those who did not, we calculated the duration of survival (in months) from the diagnostic procedure to the date of death in 28 patients without meningeal involvement. We excluded three patients in whom the diagnosis has been made recently. We found a mean duration of survival of $7 \cdot 2$ months $(95 \%$ confidence interval: 3.8-10.6 months) for 25 patients. No significant difference in survival could be found between patients with meningeal involvement and those without.
Necropsy findings were available in four patients $(1,2,5,6)$. Three of them $(1,5,6)$ had evidence of multifocal systemic lymphoma. One untreated patient (1) showed leptomeningeal involvement and tumour cells in Virchow-Robin spaces. In one treated patient (2) no evidence of metastatic lymphoma could be found. One treated patient (6) had both leptomeningeal involvement and intracerebral metastases in the brainstem, another treated patient (5) showed leptomeningeal involvement.

\section{Discussion}

When systemic non-Hodgkin's lymphoma occurs, it is often an early complication of HIV-infection; no previous AIDS-defining diagnoses had occurred in 55\% (range between reports $32-77 \%$ ) of cases. ${ }^{1}{ }^{7-9} 1314$ The overall median survival of AIDS patients with systemic intermediate or high grade NHL is 4-7 months; factors predictive of survival differ among reports and include histological subtype, initial staging, bone marrow involvement, previous AIDS diagnosis, CD4 counts, Karnofski performance status, treatment regime and response to treatment. ${ }^{1-9}{ }^{13-15}$ About half of them achieved complete remission following treatment, but relapses are frequent. The cause of death is either progressive lymphoma or opportunistic infection or both.

In non-AIDS patients risk factors for meningeal involvement include aggressive histopathological subtype, ${ }^{4-616}$ stage IV disease $^{46}$ and bone marrow involvement ${ }^{4616}$ at initial presentation.

Patients with AIDS often have aggressive and widespread systemic lymphoma. ${ }^{17-913} 14$ Bone marrow involvement at initial staging cannot be used to select patients who may be at high risk for lymphomatous meningitis. This association is not uniformly found in patients with AIDS. ${ }^{891415}$

The clinical presentation of meningeal involvement in our patients corresponds well with previous reports. ${ }^{46}$

The prognosis of lymphomatous meningitis is extremely poor. In our population mean survival was only five weeks. Survival was shortest in those patients who received no treatment at all; in both patients treatment was not initiated because of a poor condition and the presence of progressive systemic disease. However, the marginally longer survival in our six treated patients consisted of a period of hospitalisation with at most a shortlived and slight clinical improvement.

No significant decrease in survival could be found in patients who eventually developed lymphomatous meningitis, compared with those who did not, but numbers are small. To improve survival, prevention of meningeal relapse in patients with a fair or good prognosis of systemic disease may be important. A recent prospective trial in AIDS patients who all had a lumbar puncture for staging showed that the combination of a less aggressive systemic chemotherapeutic schedule, pro- 
phylactic intrathecal treatment, an appropriate antiretroviral medication and prophylactic treatment of opportunistic infections seems promising. No meningeal relapses were seen in those patients who had a partial or complete remission ( $51 \%$ of all patients) after treatment. ${ }^{7}$ Nevertheless, median survival in this series (6.5 months) did not differ much from that found in the above retrospective series. ${ }^{189}{ }^{13-15}$

Lymphomatous meningitis frequently occurs in AIDS-related systemic nonHodgkin's lymphoma. It still is a rare neurological complication of AIDS, but the incidence has risen in recent years. Among all neurological complications, lymphomatous meningitis has the bleakest outcome, with a mean survival of only five weeks, and no patient surviving more than 14 weeks in our population. Our experience seems to justify every trial with the intention of preventing this complication in systemic lymphoma.

We would like to express our appreciation to Professor Dr $M$ de Visser for her critical comments, and to $P$ van Halem of the Office of Medical Registration for providing data on prevalence of systemic non-Hodgkin's lymphoma at the Academic Medical Centre of Amsterdam from 1982 until the present.

1 Ziegler JL, Beckstead JA, Volberding PA, et al. NonHodgkin's lymphoma in 90 homosexual men: relation immunodeficiency syndrome. N Engl $f$ Med 1984; 311:565-70.

2 Ioachim HL, Dorsett B, Cronin W, Maya M, Wahl S. Acquired immunodeficiency syndrome-associated lymphomas: clinical, pathologic, immunologic, and viral characteristics of 111 cases. Hum Pathol 1991;22. 659-73.

3 Beral V, Peterman T, Berkelman R, Jaffe H. AIDS-associated non-Hodgkin lymphoma. Lancet 1991;337:805-9.

4 Sheehan T, Cuthbert RJG, Parker AC. Central nervous system involvement in haematological malignancies. Clin Lab Haematol 1989;11:331-8.

5 Johnson GJ, Oken MM, Anderson JR, O'Connell MJ, Glick JH. Central nervous system relapse in unfavourable-histology non-Hodgkin's lymphoma: is prophylaxis indicated? Lancet 1984;i1:685-7.

6 Levitt LJ, Dawson DM, Rosenthal DS, Moloney WC CNS involvement in the non-Hodgkin's lymphomas. Cancer 1980;45:545-52.

7 Levine AM, Wernz JC, Kaplan L, et al. Low-dose chemotherapy with central nervous system prophylaxis and zidovudine maintenance in AIDS-related lymphoma: A prospective multi-institutional trial. $¥ A M A$ 1991;266:84-8.

8 Lowenthal DA, Straus DJ, Campbell SW, Gold JWM, Clarkson BD, Koziner B. AIDS-related lymphoid neoplasia: The Memorial Hospital experience. Cancer 1988;61:2325-37.

9 Kaplan LD, Abrams DI, Feigal E, et al. AIDS-associated non-Hodgkin's lymphoma in San Francisco. $\mathfrak{F A M A}$ 1989;261:719-24.

10 Carbone PP, Kaplan HS, Musshoff K, Smithers DW, Tubiana M. Report of the committee on Hodgkin's disTubiana M. Report of the committee on Hodgkin's dis-

11 National Cancer Institute sponsored study of classification of non-Hodgkin's lymphomas. Summary and description of a working formulation for clinical usage. Cancer 1982;49:2112-35.

12 Lennert $\mathrm{K}$, Mohri N, Stein $\mathrm{H}$, et al. The histopathology of malignant lymphoma. Br F Haematol 1975;31:193-203.

13 Bermudez MA, Grant KM, Rodvien R, Mendes F. NonHodgkin's lymphoma in a population with or at risk for acquired immunodeficiency syndrome: Indications for intensive chemotherapy. Am $f$ Med 1989;86:71-6.

14 Knowles DM, Chamulak GA, Subar M, et al. Lymphoid neoplasia associated with the acquired immunodeficioplat ciency syndrome (AIDS): The New York University (1981-1986). Ann Int Med 1988;108:744-53.

15 Levine AM, Sullivan-Hailey J, Pike MC, et al. Human immunodeficiency virus-related lymphoma: Prognostic immunodeficiency virus-related lymphoma: Prognostic

16 Litam JP, Cabanillas F, Smith TL, Bodey GP, Freireich EJ. Central nervous system relapse in malignant lymphomas: Risk factors and implications for prophylaxis. Blood 1979;54:1249-57. 